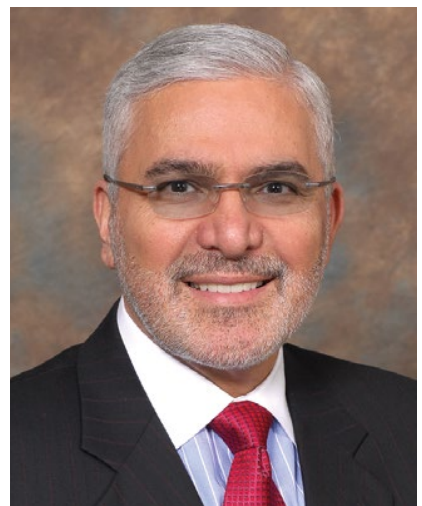

Henry A. Nasrallah, MD Editor-in-Chief doi: 10.12788/cp.0046

Is voting a purely intellectual decision (ie, cortical), or is it driven by visceral emotions (ie, limbic)?

To comment on this

\title{
Neuro-politics: Will you vote with your cortex or limbic system?
}

It's election season again. Every 4 years, October becomes the purgatory month of politics. But this year, it's even more complicated, being juxtaposed against a chaotic mosaic of a viral pandemic, economic travails, social upheaval, and exceptionally toxic political hyperpartisanship.

The widespread expectation is that citizens will vote for their party's candidates, but there is now a body of evidence suggesting that our brains may be pre-wired to be liberal or conservative.

Enter neuro-politics. This discipline is younger than neuro-economics, neuro-law, neuro-ethics, neuro-marketing, neuro-art, neuro-culture, or neuroesthetics. Neuro-politics focuses on the intersection of politics with neuroscience. ${ }^{1}$ However, there are many antecedents to neuro-politics reflected in the writings of Plato, Aristotle, Niccolò Machiavelli, John Locke, Baruch Spinoza, Henri Bergson, William James, and others.

Neuro-politics attempts to generate data to answer a variety of questions about political behavior, such as:

- Is political orientation associated with differences in certain brain regions?
- Are there reliable neural biomarkers of political orientation?

- Is political orientation modifiable, and if so, why are some individuals ferociously entrenched to one political dogma while others are able to untether themselves and adopt another political doctrine?

-What are the brain characteristics of "swing voters" who may align themselves with different parties in different election cycles?

- Is there a "religification" of politics among the ardent fanatics who regard the tenets of their political beliefs as "articles of faith?"

- Is the brain modified by certain attributes (such as educational level, age, sex, marital status, race, ethnicity, and religious affiliation) that translate to political decision-making?

- Can neuro-politics explain the sprouting of psychiatric symptoms such as obsessions, anxiety, irritability, anger, hatred, and conspiracy theories?

- Is political extremism driven by cortical structures, limbic structures, or both?

\section{Politics and the brain}

Here is a brief review of some studies that examined the relationship of political orientation or voting behavior with brain structure and function: 
1. Roger Sperry, the 1981 Nobel Laureate (for his studies on split-brain patients) reported that in patients who underwent callosotomy, both cerebral hemispheres gave the same ratings of politicians when their photos were shown to each hemisphere separately. ${ }^{2}$

2. A functional magnetic resonance imaging (fMRI) study found that the faces of candidates activated participants' ventromedial and anterior prefrontal cortices. Amygdala activation was associated with the intensity of the emotion. $^{3}$

3. A skin conductance study reported that politically liberal individuals had low reactivity to sudden noises and threatening stimuli, while conservative counterparts demonstrated high physiological reactions to noises and stimuli. ${ }^{4}$

4. Images of a losing candidate elicited greater activation on fMRI in the insula and ventral anterior cingulate compared to no activation by exposure to an image of the winning candidate. ${ }^{5}$

5. Another fMRI study found that "individualism" was associated with activation of the medial prefrontal cortex and temporo-parietal junction when participants listened to a set of political statements. On the other hand, "conservatism" activated the dorsolateral prefrontal cortex, while "radicalism" activated the ventral striatum and posterior cingulate. ${ }^{6}$

6. An EEG activity study of healthy individuals revealed desynchronization in the alpha band related to the politicians who lost simulated elections and were judged as "less trustworthy" when the participant watched their faces. ${ }^{7}$

7. A structural MRI study of young adults reported that liberalism was associated with increased gray matter volume in the anterior cingulate, while conservatism was associated with increased volume of the right amygdala. The authors replicated their findings and concluded there is a possible link between brain structure and psychological mechanisms that mediate political attitudes. ${ }^{8}$

8. To examine the effect of a "first impression" based on the physical appearance of candidates, researchers compared individuals with damage to the lateral orbitofrontal cortex (OFC) with a group that had frontal damage that spared the lateral OFC and another group of matched healthy volunteers. They used a simulated elections paradigm in which participants voted based solely on photographs of the candidates' faces. Only the group with OFC damage was influenced by attractiveness, while those with an intact frontal lobe or non-OFC frontal damage relied on other data, such as competence. ${ }^{9}$ These researchers concluded that an intact OFC is necessary for political decision-making.

9. A study using cognitive tasks reported that liberals are more adept at dealing with novel information than conservatives. ${ }^{10}$

\section{What part of your brain will you use?}

Regardless of the data generated by the neuro-politics studies, the bottom line is: What part of your brain do you use when you cast your vote for an issue, a representative, a senator, or a president? Is it a purely intellectual decision (ie, cortical), or is it driven by visceral emotions (ie, limbic)? Do you believe that every single item in your party's platform is right and virtuous, while every item in the other party's platform is wrong and evil? Can you think of any redeeming feature of the candidate you hate or the party you despise?

One attribute that we psychiatrists possess by virtue of our training and clinical work is that we are able to transcend dichotomies and to perceive nuances and shades of gray about controversial issues. So I hope
Editorial Staff

EDITOR Jeff Bauer

SENIOR EDITOR Sathya Achia Abraham

ASSISTANT EDITOR Jason Orszt

WEB ASSISTANTS

Tyler Mundhenk, Kathryn Wighton

Art \& Production Staff

CREATIVE DIRECTOR Louise Koenig

ART DIRECTOR Pat Fopma

DIRECTOR, JOURNAL MANUFACTURING Michael Wendt

PRODUCTION MANAGER Donna Pituras

Publishing Staff

PUBLISHER Sharon Finch

DIRECTOR EBUSINESS DEVELOPMENT

Alison Paton

SENIOR DIRECTOR OF SALES

Tim LaPella

Editor-in-Chief Emeritus

James Randolph Hillard, MD

Frontline Medical Communications

VP, SALES Mike Guire

VP, DIGITAL CONTENT \& STRATEGY Amy Pfeiffer

PRESIDENT, CUSTOM SOLUTIONS JoAnn Wahl

CIRCULATION DIRECTOR Jared Sonners DIRECTOR, CUSTOM PROGRAMS

Patrick Finnegan

In affiliation with Global Academy for Medical Education, LLC

PRESIDENT David J. Small, MBA

\section{FRONTLINE MCedge}

7 Century Drive, Suite 302

Parsippany, NJ 07054

Tel: (973) 206-3434

Fax: (973) 206-9378

www.frontlinemedcom.com

Subscription Inquiries:

subscriptions@mdedge.com

Published through an

educational partnership with

l(C CINCINNATI

Current Psychiatry

Vol. 19, No. 10 15 
From the Editor

continued from page 15

we employ the circuits of our brain where wisdom putatively resides ${ }^{11}$ and which may develop further (via neuroplasticity) with the conduct of psychotherapy. ${ }^{12}$ Those brain circuits include:

- prefrontal cortex (for emotional regulation, decision-making, and value relativism)

- lateral prefrontal cortex (to facilitate calculated, reason-based decision-making)

- medial prefrontal cortex (for emotional valence and pro-social attitudes and behaviors).

However, being human, it is quite likely that our amygdala may "seep through" and color our judgment and decisions. But let us try to cast a vote that is not only good for the country but also good for our patients, many of whom may not even be able to vote. Election season is a time to make a positive difference in our patients' lives, not just ours. Let's hope our brains exploit this unique opportunity.

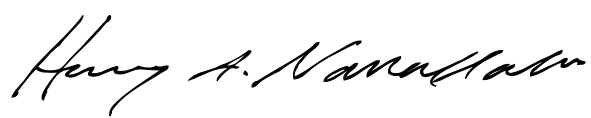

Henry A. Nasrallah, MD

Editor-in-Chief

\section{References}

1. Schreiber D. Neuropolitics: twenty years later. Politics Life Sci. 2017;36(2):114-131.

2. Sperry RW, Zaidel E, Zaidel D. Self recognition and social awareness in the deconnected minor hemisphere. Neuropsychologia. 1979;17(2):153-166.

3. Knutson KM, Wood JN, Spampinato MV, et al. Politics on the brain: an FMRI investigation. Soc Neurosci. 2006;1(1): 25-40

4. Oxley DR, Smith KB, Alford JR, et al. Political attitudes vary with physiological traits. Science. 2008;321(5896): 1667-1670

5. Spezio ML, Rangel A, Alvarez RM, et al. A neural basis for the effect of candidate appearance on election outcomes. Soc Cogn Affect Neurosci. 2008;3(4): 344-352.

6. Zamboni G, Gozzi M, Krueger F, et al. Individualism, conservatism, and radicalism as criteria for processing political beliefs: a parametric fMRI study. Soc Neurosci. 2009;4(5):367-383.

7. Vecchiato G, Toppi J, Cincotti F, et al. Neuropolitics: EEG spectral maps related to a political vote based on the first impression of the candidate's face. Conf Proc IEEE Eng Med Biol Soc. 2010;2010:2902-2905

8. Kanai R, Feilden T, Firth $C$, et al. Political orientations are correlated with brain structure in young adults. Curr Biol. 2011;21(8):677-680.

9. Xia C, Stolle D, Gidengil E, et al. Lateral orbitofrontal cortex links social impressions to political choices. J Neurosci. 2015;35(22):8507-8514.

10. Bernabel RT, Oliveira A. Conservatism and liberalism predict performance in two nonideological cognitive tasks. Politics Life Sci. 2017;36(2):49-59.

11. Meeks TW, Jeste DV. Neurobiology of wisdom: a literature overview. Arch Gen Psychiatry. 2009;66(4):355-365

12. Nasrallah HA. Does psychiatric practice make us wiser? Current Psychiatry. 2009;8(10):12,14
Election season is a time to make a positive difference in our patients' lives, not just ours 